\title{
STRESS ANALYSIS PISTON SEPEDA MOTOR MENGGUNAKAN SOFTWARE AUTODESK INVENTOR 2015
}

\author{
Asroni ${ }^{1 *}$, Dwi Irawan ${ }^{2}$ \\ Jurusan Teknik Mesin, Fakultas Teknik, Universitas Muhammadiyah Metro ${ }^{1,2}$ \\ Jl. Ki Hajar Dewantara 15 A Metro, Lampung \\ e-mail : asroni@engineer.com¹, dwi_irawan@yahoo.co.id ${ }^{2}$
}

\begin{abstract}
Abstrak
Modifikasi adalah cara merubah bentuk suatu benda atau barang dari bentuk awal dengan bentuk selanjutnya yang berbeda agar berbeda tanpa menghilangkan fungsi asli dari benda atau barang tersebut. Objek yang sering digunakan biasanya sepeda motor, sebagai contoh modifikasi ruang bakar. Melihat kondisi di lapangan seringkali pada saat modifikasi tidak menghiraukan atau tidak mengetahui bagaimana kerusakan akibat dari hasil modifikasi ruang bakar tersebut. Akibatnya kerusakan pada ruang bakar sering terjadi seperti rusaknya piston akibat thermal ataupun tekanan yang berlebihan. Tujuan penelitian ini adalah mengetahui pengaruh modifikasi ruang bakar terhadap tegangan, regangan, dan deformasi pada piston. Penelitian ini menggunakan metode simulasi, dengan jenis sepeda motor merk Honda tipe Revo 100cc tahun 2008, dengan cara mengikis pada head cylinder. Nilai pengikisan tidak dikikis (standard);0,1;0,2;0,3;0,4 dan $0,5 \mathrm{~mm}$. Hasil penelitian ini mengakibatkan perubahan nilai kompresi di tiap ukuran pengikisannya dan akibat dari pengikisan tersebut yaitu: 147 Psi dengan nilai tegangan 633,64 Mpa, regangan 0,00573415 ul, deformasi $0,0228577 \mathrm{~mm}$. 156 Psi dengan nilai tegangan 672,434 Mpa, regangan $0,00608522 \mathrm{ul}$, deformasi $0,0242572 \mathrm{~mm}$. $167 \mathrm{Psi}$, dengan nilai tegangan 719,849 Mpa, regangan $0,0065143 \mathrm{ul}$, deformasi $0,025976 \mathrm{~mm}$. $177 \mathrm{Psi}$, dengan nilai tegangan 762,954 Mpa, regangan 0,00690438 ul, deformasi 0,0275228 mm. $186 \mathrm{Psi}$, dengan nilai tegangan $801,748 \mathrm{Mpa}$, regangan 0,00725545 ul, deformasi 0,028922 mm. 192 Psi, dengan nilai tegangan 827,611 Mpa, regangan 0,0079895 ul, deformasi 0,029855 mm..
\end{abstract}

Kata kunci: Piston, Motor Bakar, Simulasi, Autodesk Inventor 2015, Modifikasi Ruang Bakar.

\section{Pendahuluan}

Motor bakar adalah salah satu jenis dari mesin kalor [1]. Rasio kompresi pada motor bakar dipengaruhi oleh volume ruang bakar yang berubah, semakin kecil volume ruang bakar, maka rasio kompresi akan semakin tinggi. Kompresi yang semakin tinggi tentu akan mengakibatkan karakteristik pada piston [2].

\section{Tinjauan Teoritis}

Pada penelitian sebelumnya oleh Aprinaldi; 2015, penelitian dengan menganalisa pengaruh modifikasi kepala silinder terhadap campuran bahan bakarudara pada mesin Honda GX-160.
Penelitian itu dilakukan dengan cara memotong kepala silinder sebesar 0,1 , $0,2,0,3,0,4$, dan $0,5 \mathrm{~mm}$ yang akan memperkecil ruang bakar sehingga mempertinggi kompresi [3]. penelitian terdahulu oleh Asep Syarif Hidayattulah; 2012, penelitian ini menganalisa Pengaruh Proses Oversize Piston Terhadap Kinerja Motor dan Pengujian Ketahanan Mekanik Piston dengan Menggunakan Perangkat Lunak Catia V5R14. Proses analisa tersebut lebih tertuju pada oversize piston serta analisis pengujian ketahanan mekanik piston dengan menggunakan perangkat lunak Catia [4]. 
Piston

Adalah komponen penghisap bahan bakar, menghasilkan kompresi, menerima tenaga hasil pembakaran, dan membuang gas hasil pembakaran. Piston berfungsi menjaga tekanan kompresi dan menyalurkan panas piston ke blok silinder [5].

\section{Kepala Silinder}

Kepala silinder berfungsi sebagai tempat ruang bakar, tutup blok silinder, dan tempat komponen-komponen mekanik katup [5].

\section{Kompresi}

Kompresi pada mesin merupakan tekanan udara dan bahan bakar pada ruang bakar. Ada pula pengertian rasio kompresi, rasio kompresi adalah perbandingan volume ruang bakar saat piston di titik mati bawah (TMB) dengan volume ruang bakar saat titik mati atas (TMA). Semakin besar perbandingan rasio kompresi maka pada saat piston berada di titik mati atas (TMA) akan memiliki tekanan dan suhu yang semakin besar pula [3].

\section{Pembebanan}

Pembebanan pada sebuah komponen dapat dibagi dalam beberapa model pembebanan seperti pembebanan aksial, pembebanan dengan momen tekuk (bending moment), dan pembebanan dengan torsi. Model-model pembebanan ini pada suatu komponen, mempunyai pengaruh yang besar dalam desain suatu komponen [6]. Tegangan dan Regangan adalah konsep yang penting dalam peninjauan baik kekuatan maupun kekakuan. Keduanya merupakan konsekuensi yang tidak dapat dipisahkan dari bekerjanya suatu beban terhadap suatu bahan struktur. Tegangan dapat dianggap sebagai sebuah energi yang menahan beban; Regangan adalah ukuran deformasi yang terjadi sebagai akibat tegangan. Dalam suatu elemen struktur, tegangan adalah gaya dalam dibagi dengan luas penampang di mana gaya itu bekerja. Oleh karena itu, Tegangan dianggap sebagai efek bertumpuk dari tegangan.

Kekuatan bahan dapat diukur dengan tegangan maksimum yang dapat ditahannya-kekuatan ini disebut juga tegangan runtuh (gagal). Kekuatan dari suatu elemen struktur diukur dari gaya dalam maksimum yang dapat ditahannya. Hal ini tergantung pada kekuatan bahan penyusunnya dan ukuran serta bentuk penampangnya. Kekuatan puncak dari elemen dicapai ketika tegangan melebihi tegangan runtuh dari bahan [7].

\section{Metode Penelitian}

Langkah-langkah dalam melakukan penelitian yaitu:

1. Menyiapkan alat dan bahan.

2. Pengikisan Kepala Silinder.

3. Pengukuran dimensi piston.

4. Menggambar piston.

5. Melakukan simulasi dengan Software Inventor 2015.

6. Mengolah data

Pada kepala silinder, pengikisan dilakukan dengan memvariasikan ukuran pada pengikisan kepala silinder. Variasi pengikisan tersebut diambil data ukur sebesar 0,1, 0,2, 0,3, 0,4, dan 0,5 mm. Hal tersebut bertujuan untuk memperkecil ruang bakar sehingga mempertinggi kompresi.

Tabel 1. Physical Properties [4]

\begin{tabular}{|l|l|}
\hline Material & AC8A \\
\hline Young Modulus $\left(\mathrm{N} / \mathrm{m}^{2}\right)$ & $9.1 \times 10^{10}$ \\
\hline Poisson Ratio & 0.346 \\
\hline Density $\left(\mathrm{kg} / \mathrm{m}^{3}\right)$ & 2710 \\
\hline $\begin{array}{l}\text { Thermal Expansion } \\
\left({ }^{\circ} \mathrm{C}\right)\end{array}$ & $21.0 \times 10^{-6} /{ }^{\circ} \mathrm{C}$ \\
\hline Yield Strength $\left(\mathrm{N} / \mathrm{m}^{2}\right)$ & $9.5 \times 10^{7}$ \\
\hline
\end{tabular}


Sifat fisika suatu logam adalah bagaimana keadaan logam itu apabila mengalami peristiwa fisika [8].

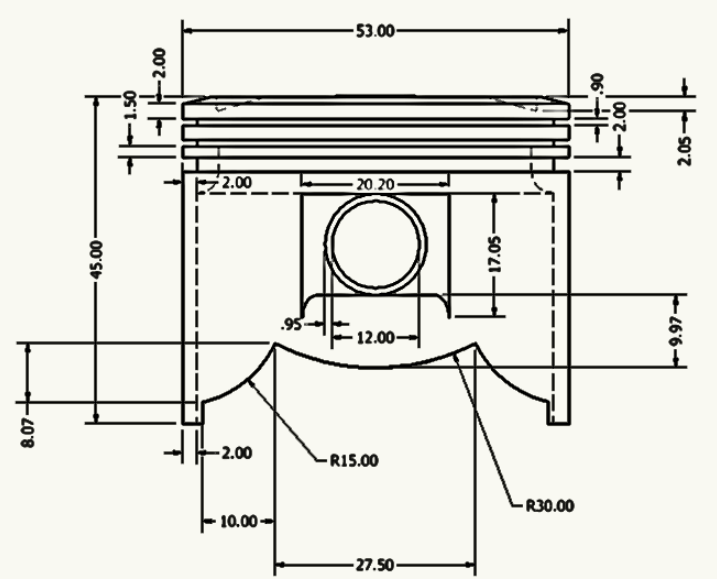

Gambar 1. Dimensi Piston

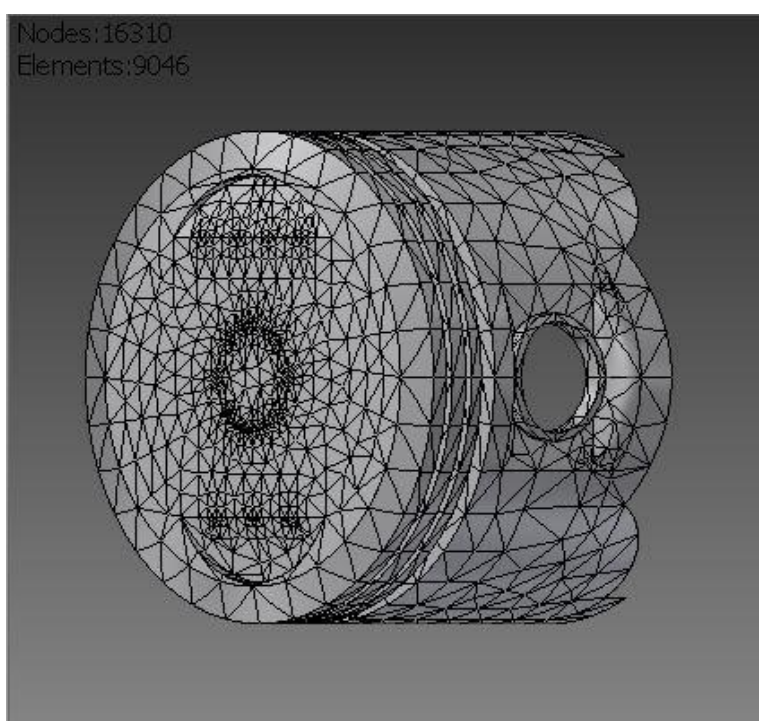

Gambar 2. Mesh

\section{Hasil dan Pembahasan}

Untuk mengetahui karakteristik pada piston dengan pengaruh pengikisan kepala silinder dan memvariasikan pengikisan head silinder dengan ukuran pengikisan $0,1 \mathrm{~mm} \mathrm{0,2} \mathrm{mm} 0,3 \mathrm{~mm} 0,4$ $\mathrm{mm}$ dan $0,5 \mathrm{~mm}$ agar di dapat tekanan yang berbeda untuk kemudian di simulasikan. Adapun hasil pengujian yang diperoleh dalam bentuk data-data berikut:
Pengambilan data kompresi ruang bakar dicatat pada saat kondisi motor mati karena busi dilepas, kemudian diambil data dengan menggunakan alat kompresi tester. Data hasil pengujian diambil dari nilai tertinggi dari ukuran pengikisan yang berbeda.

Tabel 2. Data Kompresi Hasil Pengikisan Kepala Silinder

\begin{tabular}{|c|c|c|c|c|}
\hline No & $\begin{array}{c}\text { Ukuran } \\
\text { Pengikisan }\end{array}$ & Pengujian & $\begin{array}{l}\text { Hasil } \\
\text { (PS) }\end{array}$ & $\begin{array}{l}\text { Hasil Pengujian } \\
\text { Rata-rata (PSI) }\end{array}$ \\
\hline \multirow{5}{*}{1} & \multirow{5}{*}{ Standar } & 1 & 144 & \multirow{5}{*}{147} \\
\hline & & 2 & 145 & \\
\hline & & 3 & 150 & \\
\hline & & 4 & 147 & \\
\hline & & 5 & 149 & \\
\hline \multirow{5}{*}{2} & \multirow{5}{*}{$0,1 \mathrm{~mm}$} & 1 & 153 & \multirow{5}{*}{156} \\
\hline & & 2 & 156 & \\
\hline & & 3 & 155 & \\
\hline & & 4 & 154 & \\
\hline & & 5 & 160 & \\
\hline \multirow{5}{*}{3} & \multirow{5}{*}{$0,2 \mathrm{~mm}$} & 1 & 168 & \multirow{5}{*}{167} \\
\hline & & 2 & 170 & \\
\hline & & 3 & 167 & \\
\hline & & 4 & 164 & \\
\hline & & 5 & 166 & \\
\hline \multirow{5}{*}{4} & \multirow{5}{*}{$0,3 \mathrm{~mm}$} & 1 & 177 & \multirow{5}{*}{177} \\
\hline & & 2 & 180 & \\
\hline & & 3 & 178 & \\
\hline & & 4 & 174 & \\
\hline & & 5 & 176 & \\
\hline \multirow{5}{*}{5} & \multirow{5}{*}{$0,4 \mathrm{~mm}$} & 1 & 187 & \multirow{5}{*}{186} \\
\hline & & 2 & 189 & \\
\hline & & 3 & 178 & \\
\hline & & 4 & 190 & \\
\hline & & 5 & 186 & \\
\hline \multirow{5}{*}{6} & \multirow{5}{*}{$0,5 \mathrm{~mm}$} & 1 & 190 & \multirow{5}{*}{192} \\
\hline & & 2 & 189 & \\
\hline & & 3 & 192 & \\
\hline & & 4 & 195 & \\
\hline & & 5 & 194 & \\
\hline
\end{tabular}

Tabel 3. Tegangan Pada Piston

\begin{tabular}{|l|c|c|c|c|}
\hline No & $\begin{array}{c}\text { Pengikisan } \\
(\mathrm{mm})\end{array}$ & $\begin{array}{c}\text { Stress } \\
(\mathrm{Mpa})\end{array}$ & $\begin{array}{c}\text { Maximum } \\
\text { Stress } \\
(\mathrm{Mpa})\end{array}$ & $\begin{array}{c}\text { Minimum } \\
\text { Stress } \\
(\mathrm{Mpa})\end{array}$ \\
\hline 1. & Standar & 633,64 & 301,05 & $-413,99$ \\
\hline 2. & 0,1 & 672,43 & 319,45 & $-439,33$ \\
\hline 3. & 0,2 & 719,85 & 342,01 & 470,31 \\
\hline 4. & 0,3 & 762,95 & 362,49 & 498,47 \\
\hline 5. & 0,4 & 801,75 & 380,92 & 523,82 \\
\hline 6. & 0,5 & 827,21 & 393,21 & 540,71 \\
\hline
\end{tabular}




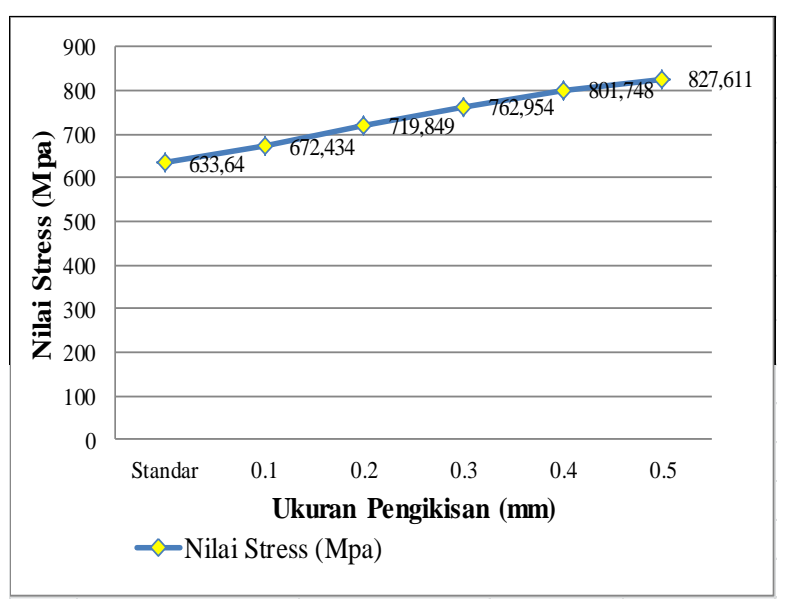

Gambar 3. Grafik hubungan antara ukuran pengikisan terhadap nilai Normal Stress

Tabel 4. Result Summary Ukuran Standar

\begin{tabular}{|c|c|c|}
\hline Name & Minimum & Maximum \\
\hline Volume & \multicolumn{2}{|l|}{$25903,2 \mathrm{~mm}^{\wedge} 3$} \\
\hline Mass & \multicolumn{2}{|l|}{$0,0350988 \mathrm{~kg}$} \\
\hline Von Mises Stress & $0,21224 \mathrm{MPa}$ & $633,64 \mathrm{MPa}$ \\
\hline 1st Principal Stress & $-3,83478 \mathrm{MPa}$ & $90,1465 \mathrm{MPa}$ \\
\hline 3rd Principal Stress & $-638,985 \mathrm{MPa}$ & $2,21765 \mathrm{MPa}$ \\
\hline Displacement & $0 \mathrm{~mm}$ & $0,0228577 \mathrm{~mm}$ \\
\hline Safety Factor & $0,149928 \mathrm{ul}$ & $15 \mathrm{ul}$ \\
\hline Stress XX & $-30,672 \mathrm{MPa}$ & $39,1438 \mathrm{MPa}$ \\
\hline Stress XY & $-34,6999 \mathrm{MPa}$ & $33,9636 \mathrm{MPa}$ \\
\hline Stress XZ & $-26,1512 \mathrm{MPa}$ & $47,2359 \mathrm{MPa}$ \\
\hline Stress $Y Y$ & $-273,47 \mathrm{MPa}$ & $49,3597 \mathrm{MPa}$ \\
\hline Stress YZ & $-198,181 \mathrm{MPa}$ & $301,048 \mathrm{MPa}$ \\
\hline Stress ZZ & $-413,986 \mathrm{MPa}$ & $73,7897 \mathrm{MPa}$ \\
\hline X Displacement & $-0,020551 \mathrm{~mm}$ & $0,0201723 \mathrm{~mm}$ \\
\hline Y Displacement & $-0,0111532 \mathrm{~mm}$ & $0,00219529 \mathrm{~mm}$ \\
\hline Z Displacement & $-0,0149 \mathrm{~mm}$ & $0,0147653 \mathrm{~mm}$ \\
\hline Equivalent Strain & $0,00000196239 \mathrm{ul}$ & 0,00573415 ul \\
\hline 1st Principal Strain & $-0,0000421404$ ul & $0,000990619 \mathrm{ul}$ \\
\hline 3rd Principal Strain & $-0,0070218$ ul & $0,0000243697 \mathrm{ul}$ \\
\hline Strain XX & $-0,000337054 \mathrm{ul}$ & $0,000430151 \mathrm{ul}$ \\
\hline Strain $X Y$ & $-0,000381316$ ul & 0,000373226 ul \\
\hline Strain XZ & $-0,000287375$ ul & 0,000519075 ul \\
\hline Strain $Y Y$ & $-0,00300516 \mathrm{ul}$ & $0,000542413 \mathrm{ul}$ \\
\hline Strain YZ & $-0,00217781 \mathrm{ul}$ & $0,00330822 \mathrm{ul}$ \\
\hline Strain ZZ & $-0,00454929 \mathrm{ul}$ & 0,000810875 ul \\
\hline
\end{tabular}

Tabel 5. Result Summary Ukuran $0,1 \mathrm{~mm}$

\begin{tabular}{|c|c|c|}
\hline Name & Minimum & Maximum \\
\hline Volume & \multicolumn{2}{|l|}{$25903,2 \mathrm{~mm}^{\wedge} 3$} \\
\hline Mass & \multicolumn{2}{|l|}{$0,0350988 \mathrm{~kg}$} \\
\hline Von Mises Stress & $0,225234 \mathrm{MPa}$ & $672,434 \mathrm{MPa}$ \\
\hline 1st Principal Stress & $-4,06957 \mathrm{MPa}$ & $95,6657 \mathrm{MPa}$ \\
\hline 3rd Principal Stress & $-678,107 \mathrm{MPa}$ & $2,35342 \mathrm{MPa}$ \\
\hline Displacement & $0 \mathrm{~mm}$ & $0,0242572 \mathrm{~mm}$ \\
\hline Safety Factor & $0,141278 \mathrm{ul}$ & $15 \mathrm{ul}$ \\
\hline Stress XX & $-32,5499 \mathrm{MPa}$ & $41,5404 \mathrm{MPa}$ \\
\hline Stress $X Y$ & $-36,8243 \mathrm{MPa}$ & $36,043 \mathrm{MPa}$ \\
\hline Stress XZ & $-27,7523 \mathrm{MPa}$ & $50,1279 \mathrm{MPa}$ \\
\hline Stress YY & $-290,213 \mathrm{MPa}$ & $52,3817 \mathrm{MPa}$ \\
\hline Stress YZ & $-210,314 \mathrm{MPa}$ & $319,48 \mathrm{MPa}$ \\
\hline Stress ZZ & $-439,332 \mathrm{MPa}$ & $78,3075 \mathrm{MPa}$ \\
\hline $\mathrm{X}$ Displacement & $-0,0218093 \mathrm{~mm}$ & $0,0214074 \mathrm{~mm}$ \\
\hline Y Displacement & $-0,0118361 \mathrm{~mm}$ & $0,00232969 \mathrm{~mm}$ \\
\hline Z Displacement & $-0,0158122 \mathrm{~mm}$ & $0,0156693 \mathrm{~mm}$ \\
\hline Equivalent Strain & $0,00000208254 \mathrm{ul}$ & $0,00608522 \mathrm{ul}$ \\
\hline 1st Principal Strain & $-0,0000447205 \mathrm{ul}$ & $0,00105127 \mathrm{ul}$ \\
\hline 3rd Principal Strain & $-0,00745171 \mathrm{ul}$ & $0,0000258618 \mathrm{ul}$ \\
\hline Strain XX & $-0,00035769 \mathrm{ul}$ & $0,000456487 \mathrm{ul}$ \\
\hline Strain $X Y$ & $-0,000404662 \mathrm{ul}$ & $0,000396077 \mathrm{ul}$ \\
\hline Strain XZ & $-0,00030497 \mathrm{ul}$ & $0,000550855 \mathrm{ul}$ \\
\hline Strain $Y Y$ & $-0,00318915 \mathrm{ul}$ & $0,000575622 \mathrm{ul}$ \\
\hline Strain YZ & $-0,00231114 \mathrm{ul}$ & $0,00351076 \mathrm{ul}$ \\
\hline Strain ZZ & $-0,00482782 \mathrm{ul}$ & $0,00086052 \mathrm{ul}$ \\
\hline
\end{tabular}

Tabel 6. Result Summary Ukuran 0,2 mm

\begin{tabular}{|c|c|c|}
\hline Name & Minimum & Maximum \\
\hline Volume & \multicolumn{2}{|l|}{$25903,2 \mathrm{~mm}^{\wedge} 3$} \\
\hline Mass & \multicolumn{2}{|l|}{$0,0350988 \mathrm{~kg}$} \\
\hline Von Mises Stress & $0,241116 \mathrm{MPa}$ & $719,849 \mathrm{MPa}$ \\
\hline 1st Principal Stress & $-4,35653 \mathrm{MPa}$ & $102,411 \mathrm{MPa}$ \\
\hline 3rd Principal Stress & $-725,922 \mathrm{MPa}$ & $2,51937 \mathrm{MPa}$ \\
\hline Displacement & $0 \mathrm{~mm}$ & $0,0259676 \mathrm{~mm}$ \\
\hline Safety Factor & $0,131972 \mathrm{ul}$ & $15 \mathrm{ul}$ \\
\hline Stress XX & $-34,8451 \mathrm{MPa}$ & $44,4695 \mathrm{MPa}$ \\
\hline Stress $X Y$ & $-39,4209 \mathrm{MPa}$ & $38,5845 \mathrm{MPa}$ \\
\hline Stress XZ & $-29,7092 \mathrm{MPa}$ & $53,6626 \mathrm{MPa}$ \\
\hline Stress $Y Y$ & $-310,677 \mathrm{MPa}$ & $56,0753 \mathrm{MPa}$ \\
\hline Stress YZ & $-225,144 \mathrm{MPa}$ & $342,007 \mathrm{MPa}$ \\
\hline Stress ZZ & $-470,311 \mathrm{MPa}$ & $83,8292 \mathrm{MPa}$ \\
\hline X Displacement & $-0,0233471 \mathrm{~mm}$ & $0,0229169 \mathrm{~mm}$ \\
\hline Y Displacement & $-0,0126707 \mathrm{~mm}$ & $0,00249397 \mathrm{~mm}$ \\
\hline Z Displacement & $-0,0169272 \mathrm{~mm}$ & $0,0167742 \mathrm{~mm}$ \\
\hline Equivalent Strain & 0,00000222939 ul & $0,0065143 \mathrm{ul}$ \\
\hline 1st Principal Strain & $-0,0000478738 \mathrm{ul}$ & 0,0011254 ul \\
\hline 3rd Principal Strain & $-0,00797715 \mathrm{ul}$ & $0,0000276853 \mathrm{ul}$ \\
\hline Strain XX & $-0,000382912 \mathrm{ul}$ & $0,000488675 \mathrm{ul}$ \\
\hline Strain $X Y$ & $-0,000433196$ ul & 0,000424005 ul \\
\hline Strain XZ & $-0,000326474$ ul & $0,000589697 \mathrm{ul}$ \\
\hline Strain $Y Y$ & $-0,00341403$ ul & $0,000616211 \mathrm{ul}$ \\
\hline Strain YZ & $-0,00247411$ ul & $0,00375831 \mathrm{ul}$ \\
\hline Strain ZZ & $-0,00516824$ ul & $0,000921198 \mathrm{ul}$ \\
\hline
\end{tabular}


Tabel 7. Result Summary Ukuran 0,3 mm

\begin{tabular}{|c|c|c|}
\hline Name & Minimum & Maximum \\
\hline Volume & \multicolumn{2}{|l|}{$25903,2 \mathrm{~mm}^{\wedge} 3$} \\
\hline Mass & \multicolumn{2}{|l|}{$0,0350988 \mathrm{~kg}$} \\
\hline Von Mises Stress & $0,255554 \mathrm{MPa}$ & $762,954 \mathrm{MPa}$ \\
\hline 1st Principal Stress & $-4,61739 \mathrm{MPa}$ & $108,544 \mathrm{MPa}$ \\
\hline 3rd Principal Stress & $-769,39 \mathrm{MPa}$ & $2,67023 \mathrm{MPa}$ \\
\hline Displacement & $0 \mathrm{~mm}$ & $0,0275226 \mathrm{~mm}$ \\
\hline Safety Factor & 0,124516 ul & 15 ul \\
\hline Stress XX & $-36,9316 \mathrm{MPa}$ & $47,1323 \mathrm{MPa}$ \\
\hline Stress $X Y$ & $-41,7815 \mathrm{MPa}$ & $40,895 \mathrm{MPa}$ \\
\hline Stress XZ & $-31,4882 \mathrm{MPa}$ & $56,8759 \mathrm{MPa}$ \\
\hline Stress $Y Y$ & $-329,28 \mathrm{MPa}$ & $59,4331 \mathrm{MPa}$ \\
\hline Stress YZ & $-238,626 \mathrm{MPa}$ & $362,487 \mathrm{MPa}$ \\
\hline Stress ZZ & $-498,473 \mathrm{MPa}$ & $88,8489 \mathrm{MPa}$ \\
\hline X Displacement & $-0,0247451 \mathrm{~mm}$ & $0,0242892 \mathrm{~mm}$ \\
\hline Y Displacement & $-0,0134294 \mathrm{~mm}$ & $0,00264331 \mathrm{~mm}$ \\
\hline Z Displacement & $-0,0179408 \mathrm{~mm}$ & $0,0177787 \mathrm{~mm}$ \\
\hline Equivalent Strain & $0,00000236288 \mathrm{ul}$ & $0,00690438 \mathrm{ul}$ \\
\hline 1st Principal Strain & $-0,0000507405$ ul & 0,00119279 ul \\
\hline 3rd Principal Strain & $-0,00845482 \mathrm{ul}$ & $0,0000293431 \mathrm{ul}$ \\
\hline Strain XX & $-0,000405841$ ul & $0,000517937 \mathrm{ul}$ \\
\hline Strain $X Y$ & $-0,000459136$ ul & $0,000449395 \mathrm{ul}$ \\
\hline Strain XZ & $-0,000346024$ ul & $0,000625009 \mathrm{ul}$ \\
\hline Strain $Y Y$ & $-0,00361846 \mathrm{ul}$ & $0,000653109 \mathrm{ul}$ \\
\hline Strain YZ & $-0,00262226 \mathrm{ul}$ & 0,00398336 ul \\
\hline Strain ZZ & $-0,00547772 \mathrm{ul}$ & 0,000976359 ul \\
\hline
\end{tabular}

Tabel 8. Result Summary Ukuran $0,4 \mathrm{~mm}$

\begin{tabular}{|c|c|c|}
\hline Name & Minimum & Maximum \\
\hline Volume & \multicolumn{2}{|l|}{$25903,2 \mathrm{~mm}^{\wedge} 3$} \\
\hline Mass & \multicolumn{2}{|l|}{$0,0350988 \mathrm{~kg}$} \\
\hline Von Mises Stress & $0,268548 \mathrm{MPa}$ & $801,748 \mathrm{MPa}$ \\
\hline 1st Principal Stress & $-4,85217 \mathrm{MPa}$ & $114,063 \mathrm{MPa}$ \\
\hline 3rd Principal Stress & $-808,512 \mathrm{MPa}$ & $2,806 \mathrm{MPa}$ \\
\hline Displacement & $0 \mathrm{~mm}$ & $0,028922 \mathrm{~mm}$ \\
\hline Safety Factor & $0,118491 \mathrm{ul}$ & $15 \mathrm{ul}$ \\
\hline Stress XX & $-38,8095 \mathrm{MPa}$ & $49,5289 \mathrm{MPa}$ \\
\hline Stress $X Y$ & $-43,9059 \mathrm{MPa}$ & $42,9744 \mathrm{MPa}$ \\
\hline Stress XZ & $-33,0893 \mathrm{MPa}$ & $59,7679 \mathrm{MPa}$ \\
\hline Stress YY & $-346,024 \mathrm{MPa}$ & $62,4551 \mathrm{MPa}$ \\
\hline Stress YZ & $-250,759 \mathrm{MPa}$ & $380,918 \mathrm{MPa}$ \\
\hline Stress ZZ & $-523,819 \mathrm{MPa}$ & $93,3666 \mathrm{MPa}$ \\
\hline X Displacement & $-0,0260033 \mathrm{~mm}$ & $0,0255242 \mathrm{~mm}$ \\
\hline Y Displacement & $-0,0141122 \mathrm{~mm}$ & $0,00277771 \mathrm{~mm}$ \\
\hline Z Displacement & $-0,018853 \mathrm{~mm}$ & $0,0186827 \mathrm{~mm}$ \\
\hline Equivalent Strain & 0,00000248303 ul & $0,00725545 \mathrm{ul}$ \\
\hline 1st Principal Strain & $-0,0000533205 \mathrm{ul}$ & $0,00125344 \mathrm{ul}$ \\
\hline 3rd Principal Strain & $-0,00888473$ ul & $0,0000308352 \mathrm{ul}$ \\
\hline Strain XX & $-0,000426477$ ul & $0,000544273 \mathrm{ul}$ \\
\hline Strain $X Y$ & $-0,000482482 \mathrm{ul}$ & $0,000472245 \mathrm{ul}$ \\
\hline Strain XZ & $-0,000363618$ ul & $0,000656789 \mathrm{ul}$ \\
\hline Strain $Y Y$ & $-0,00380245$ ul & $0,000686319 \mathrm{ul}$ \\
\hline Strain $Y Z$ & $-0,00275559$ ul & $0,00418591 \mathrm{ul}$ \\
\hline Strain ZZ & $-0,00575625$ ul & $0,001026 \mathrm{ul}$ \\
\hline
\end{tabular}

Tabel 9. Result Summary Ukuran 0,5 mm

\begin{tabular}{|c|c|c|}
\hline Name & Minimum & Maximum \\
\hline Volume & \multicolumn{2}{|l|}{$25903,2 \mathrm{~mm}^{\wedge} 3$} \\
\hline Mass & \multicolumn{2}{|l|}{$0,0350988 \mathrm{~kg}$} \\
\hline Von Mises Stress & $0,277211 \mathrm{MPa}$ & $827,611 \mathrm{MPa}$ \\
\hline 1st Principal Stress & $-5,0087 \mathrm{MPa}$ & $117,742 \mathrm{MPa}$ \\
\hline 3rd Principal Stress & $-834,593 \mathrm{MPa}$ & $2,89652 \mathrm{MPa}$ \\
\hline Displacement & $0 \mathrm{~mm}$ & $0,029855 \mathrm{~mm}$ \\
\hline Safety Factor & $0,114788 \mathrm{ul}$ & $15 \mathrm{ul}$ \\
\hline Stress XX & $-40,0614 \mathrm{MPa}$ & $51,1266 \mathrm{MPa}$ \\
\hline Stress $X Y$ & $-45,3223 \mathrm{MPa}$ & $44,3606 \mathrm{MPa}$ \\
\hline Stress XZ & $-34,1567 \mathrm{MPa}$ & $61,6959 \mathrm{MPa}$ \\
\hline Stress $Y Y$ & $-357,186 \mathrm{MPa}$ & $64,4698 \mathrm{MPa}$ \\
\hline Stress YZ & $-258,848 \mathrm{MPa}$ & $393,206 \mathrm{MPa}$ \\
\hline Stress ZZ & $-540,717 \mathrm{MPa}$ & $96,3784 \mathrm{MPa}$ \\
\hline X Displacement & $-0,0268422 \mathrm{~mm}$ & $0,0263476 \mathrm{~mm}$ \\
\hline Y Displacement & $-0,0145675 \mathrm{~mm}$ & $0,00286731 \mathrm{~mm}$ \\
\hline Z Displacement & $-0,0194612 \mathrm{~mm}$ & $0,0192853 \mathrm{~mm}$ \\
\hline Equivalent Strain & 0,00000256313 ul & 0,0074895 ul \\
\hline 1st Principal Strain & $-0,0000550406 \mathrm{ul}$ & 0,00129387 ul \\
\hline 3rd Principal Strain & $-0,00917133 \mathrm{ul}$ & $0,0000318299 \mathrm{ul}$ \\
\hline Strain XX & $-0,000440234 \mathrm{ul}$ & $0,00056183 \mathrm{ul}$ \\
\hline Strain $X Y$ & $-0,000498046$ ul & 0,000487479 ul \\
\hline Strain XZ & $-0,000375348$ ul & 0,000677975 ul \\
\hline Strain $Y Y$ & $-0,00392511 \mathrm{ul}$ & 0,000708458 ul \\
\hline Strain YZ & $-0,00284448 \mathrm{ul}$ & $0,00432094 \mathrm{ul}$ \\
\hline Strain ZZ & $-0,00594193$ ul & $0,0010591 \mathrm{ul}$ \\
\hline
\end{tabular}

Deformasi maksimum terbesar terjadi pada belakang piston dengan nilai $0,0263476 \mathrm{~mm}$, dan masih dapat di terima oleh piston karena deformasi lebih kecil dari deformasi maksimal yaitu $0,126 \mathrm{~mm}$.

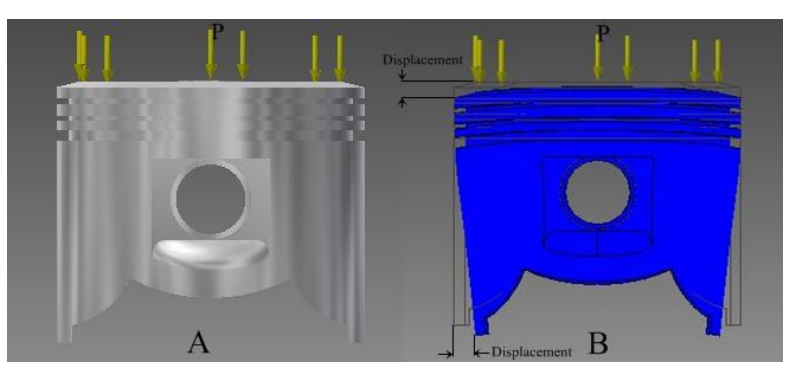

Gambar 4. Displacements

\section{Kesimpulan}

Dari hasil simulasi yang telah dilakukan, dengan pengikisan head cylinder standar, $0,1 \mathrm{~mm}, 0,2 \mathrm{~mm}, 0,3 \mathrm{~mm}, 0,4 \mathrm{~mm}$, dan $0,5 \mathrm{~mm}$. Pada judul "Pengaruh Modifikasi Ruang Bakar Sepeda Motor Terhadap Kerusakan Piston Dengan Metode Simulasi Menggunakan Perangkat Lunak Autodesk Inventor 2015" diperoleh hasil sebagai berikut: 
1. Pengaruh kompresi ruang bakar terhadap tegangan pada piston pada tekanan 147 Psi tegangan yang terjadi sebesar 633,64 Mpa, dan tegangan pada tekanan 192 Psi tegangan yang terjadi sebesar 827,611 Mpa.

2. Pengaruh kompresi ruang bakar terhadap regangan pada piston pada tekanan 147 Psi regangan yang terjadi sebesar 0,00573415 ul, dan regangan pada tekanan 192 Psi regangan yang terjadi sebesar 0,0079895 ul.

3. Pengaruh kompresi ruang bakar terhadap deformasi pada piston pada tekanan 147 Psi deformasi yang terjadi sebesar 0,0228577 $\mathrm{mm}$, dan deformasi pada tekanan 192 Psi deformasi yang terjadi sebesar $0,029855 \mathrm{~mm}$.

\section{Saran}

Simulasi yang dilakukan pada penelitian ini adalah dengan membuat model yang mirip benda sebenarnya, hasil yang diperoleh adalah sekedar pertimbangan untuk penelitian lanjut. Saran yang diberikan adalah dilakukan penelitian ulang dengan menggunakan benda uji yang nyata dan mempertimbangkan pengaruh panas terhadap kekuatan material.

\section{Daftar Pustaka}

[1] Soekardi, C. (2015). Termodinamika Dasar Mesin Konversi Energi. Yogyakarta: Penerbit Andi.

[2] Moran, M. J. (2004). Termodinamika Teknik Jl. 2. Jakarta: Erlangga.

[3] Aprinaldi, A. A. (kein Datum). Kaji Eksperimental Pengaruh Modifikasi Kepala Silinder Terhadap Campuran Bahan Bakar-Udara (Air-Fuel Ratio) (Studi Kasus Pada Mesin Honda GX-160). Doctoral dissertation. Universitas Bengkulu.
[4] Hidayattulah, A. S. (2012). Analisis Pengaruh Proses Oversize Piston Terhadap Kinerja Motor dan Pengujian Ketahanan Mekanik Piston Dengan Menggunakan Perangkat Lunak Catia V5R14. Jakarta: Gunadarma.

[5] Suwarto, T. (2008). Mencari \& Memperbaiki Kerusakan Sepeda Motor 4-Tak. Jakarta: Kawan Pustaka.

[6] Ashby, M. F. (2005). Materials Selection In Mechanical Design 3th Edition. Pergamon Press.

[7] Macdonald, A. J. (2002). Struktur dan Arsitektur Edisi Kedua. Jakarta: Erlangga.

[8] Lovell. (2012). Physical Properties of Materials. Berlin: Springer Science \& Business Media. 